This is an author produced version of a paper published in European Journal of Forest Research.

This paper has been peer-reviewed and is proof-corrected, but does not include the journal pagination.

Citation for the published paper:

Eva Lindberg, Johan Holmgren, Kenneth Olofsson, Håkan Olsson. (2012) Estimation of stem attributes using a combination of terrestrial and airborne laser scanning. European Journal of Forest Research. Volume: 131, Number: 6, pp 1917-1931.

http://dx.doi.org/10.1007/s10342-012-0642-5.

Access to the published version may require journal subscription. Published with permission from: Springer-Verlag.

Standard set statement from the publisher:

The final publication is available at www.springerlink.com at: http://download.springer.com/static/pdf/919/art\%253A10.1007\%252Fs10342-012-06425.pdf?auth66=1354869359_bb4761853b4f94301875a787ab39d651\&ext=.pdf

Epsilon Open Archive http://epsilon.slu.se 


\title{
Estimation of stem attributes using a combination of terrestrial and airborne laser scanning
}

\author{
Eva Lindberg, Johan Holmgren, \\ Kenneth Olofsson, and Håkan Olsson \\ Swedish University of Agricultural Sciences, Department of Forest \\ Resource Management, SE-90183 Umeå, Sweden
}

\begin{abstract}
Properties of individual trees can be estimated from airborne laser scanning (ALS) data provided that the scanning is dense enough and the positions of field-measured trees are available as training data. However, such detailed manual field measurements are laborious. This paper presents new methods to use terrestrial laser scanning (TLS) for automatic measurements of tree stems and to further link these ground measurements to ALS data analyzed at the single tree level. The methods have been validated in six $80 \times 80 \mathrm{~m}$ field plots in spruce-dominated forest (lat. $58^{\circ} \mathrm{N}$, long. $13^{\circ} \mathrm{E}$ ). In a first step, individual tree stems were automatically detected from TLS data. The root mean square error (RMSE) for DBH was $38.0 \mathrm{~mm}(13.1 \%)$ and the bias was $1.6 \mathrm{~mm}(0.5 \%)$. In a second step, trees detected from the TLS data were automatically co-registered and linked with the corresponding trees detected from the ALS data. In a third step, tree level regression models were created for stem attributes derived from the TLS data using independent variables derived from trees detected from the ALS data. Leave-oneout cross-validation for one field plot at a time provided an RMSE for tree level ALS estimates trained with TLS data of $46.0 \mathrm{~mm}(15.4 \%)$ for DBH, $9.4 \mathrm{dm}(3.7 \%)$ for tree height, and $197.4 \mathrm{dm}^{3}(34.0 \%)$ for stem volume, which was nearly as accurate as when data from manual field inventory were used for training.
\end{abstract}

Keywords: Airborne Laser Scanning, Terrestrial laser scanning, forest inventory, single tree detection 



\section{Introduction}

Modern remote sensing techniques such as airborne laser scanning (ALS) have made it possible to automatically delineate individual tree crowns (Hirschmugl 2008). Using a Canopy Height Model (CHM) derived from the ALS data, delineation can be done by identifying canopy height maxima and dividing the canopy into tree crown segments (Hyyppä et al. 2001; Persson et al. 2002), by fitting cone-shaped objects using a modified Hough transform (Van Leeuwen et al. 2010), or by spatial wavelet analysis (Falkowski et al. 2006). The delineation can also be done by segmentation of voxels or by clustering in three dimensions (Gupta et al. 2010; Reitberger et al. 2009). Such single tree analysis can provide tree height estimates and if field data from the laser scanned area are available, statistical models can be created to estimate variables such as diameter at breast height (DBH) and stem volume for the dominant and subdominant trees in coniferous-dominated boreal forests (Persson et al. 2002).

To connect the trees detected from the ALS data with the corresponding trees in the field, tree positions and stem attributes measured in the field are also required. This is usually achieved by allocating field plots in the forest area and measuring the position and DBH of all trees and the height of a subsample of trees (Vauhkonen et al. 2010). The measurements are done manually and even though electronic equipment may be used to save the measurements automatically, the field workers still have to measure each individual tree. Terrestrial laser scanning (TLS) offers the potential to automate tree position and stem diameter measurements. TLS is a quickly developing technique that provides highly accurate three-dimensional data consisting of distance measurements from the scanner to the surrounding surfaces.

The combination of data from TLS and ALS provides a possibility to implement a forest inventory system with minimal need for manual measurements. TLS and ALS have been combined to estimate canopy structure 
at the plot level (Hilker et al. 2010; Lovell et al. 2003). In the present study, TLS and ALS are combined at tree level. An early version of this study is presented in Lindberg et al. (2010). One of the few other studies where TLS and ALS data are combined at tree level is Fritz et al. (2011) who found that approximately one third of the trees detected from TLS could be linked to trees detected from ALS. The outcome of the linking depends partly on the algorithms used to detect trees from TLS and ALS as well as the forest density and structure. Combination of TLS and ALS data requires co-registration of the data sources. Since GPS positions measured under a canopy are less accurate, the positions of the field-collected data must be adjusted; this may be done by matching the tree positions (Olofsson et al. 2008). When using TLS data as field measurements, co-registration must take into account that the TLS data will have zones that are obscured from the scanner.

The most common way to estimate positions and stem diameters from TLS data is to first find approximate tree positions and diameters using either manual detection (Hopkinson et al. 2004), a clustering algorithm (Maas et al. 2008; Bienert et al. 2007; Király and Brolly 2007), skeletonization (Gorte and Pfeifer 2004), or the Hough transform (Aschoff et al. 2004), and then fit circles along the tree stems using least squares regression (Pfeifer et al. 2004; Henning and Radtke 2006; Watt and Donoghue 2005). Wezyk et al. (2007) modeled tree stems from TLS data by fitting convex hulls to the laser reflections and estimating DBH and basal area from the convex hulls. Thies et al. (2004) used TLS data captured at multiple positions around the centre of a sample plot to model tree stems with overlapping cylinders. The cylinders were fitted from the root of the tree and up along the stem until a preselected maximum root mean square error was exceeded. It can be expected that inventories with terrestrial laser scanners will also offer the opportunity to determine timber quality of standing trees, for example, using detailed models of tree stems and branches (e.g., Pfeifer and Winterhalder 2004).

The objective of this study is to present and validate a processing chain where TLS data are used to automatically train ALS estimates at the single tree level. Among the results presented from this processing chain are: i) validation of a new automated method to estimate DBH from TLS data, and ii) comparison of the accuracy of single tree level ALS based estimates of stem diameter and stem volume when trained with TLS data as opposed to ALS based estimates trained with manual field measurements. 


\section{Material}

\subsection{Study Area}

The study area is located in the Remningstorp estate in southern Sweden (lat. $58^{\circ} \mathrm{N}$, long. $13^{\circ} \mathrm{E}$ ). The estate covers 1200 ha of forest land on relatively fertile sites. The dominant tree species in the area is Norway spruce (Picea abies) followed by birch (Betula spp.) and Scots pine (Pinus sylvestris).

\subsection{Manual Field Inventory}

Manual field measurements were done to collect validation data. Six rectangular $80 \times 80 \mathrm{~m}$ field plots were allocated (table 1) during the Autumn of 2006 in Norway spruce dominated forest stands with almost no understory.

Table 1. Summary of manual field measurements.

\begin{tabular}{|c|c|c|c|c|c|c|c|}
\hline \multirow[t]{2}{*}{ Plot } & \multirow[t]{2}{*}{$\begin{array}{l}\text { Number } \\
\text { of trees }\end{array}$} & \multicolumn{3}{|c|}{$\begin{array}{l}\text { Species proportion } \\
\text { of basal area }(\%)\end{array}$} & \multicolumn{3}{|c|}{$\mathrm{DBH}(\mathrm{mm})$} \\
\hline & & Spruce & Pine & $\begin{array}{l}\text { Deciduo } \\
\text { us }\end{array}$ & $\begin{array}{l}\text { 10th } \\
\text { percen- } \\
\text { tile }\end{array}$ & Mean & $\begin{array}{l}\text { 90th } \\
\text { percent- } \\
\text { tile }\end{array}$ \\
\hline 1 & 369 & 87 & 10 & 3 & 230 & 322 & 411 \\
\hline 2 & 424 & 99 & 0 & 1 & 222 & 297 & 386 \\
\hline 3 & 357 & 79 & 0 & 21 & 150 & 290 & 422 \\
\hline 4 & 410 & 99 & 0 & 1 & 173 & 237 & 302 \\
\hline 5 & 384 & 98 & 0 & 2 & 130 & 233 & 315 \\
\hline 6 & 332 & 98 & 0 & 2 & 180 & 322 & 452 \\
\hline Mean & 379 & 93 & 2 & 5 & 178 & 268 & 395 \\
\hline
\end{tabular}


For all trees with $\mathrm{DBH} \geq 30 \mathrm{~mm}$ within the field plots, the tree species were recorded and the diameters were measured on two perpendicular axes using a caliper with mm accuracy. The DBH of each tree was calculated as the average of these measurements. For a subsample of the trees, height was measured using a hypsometer with sub-meter accuracy. The positions of reference points near the field plots were measured with $\mathrm{cm}$ accuracy using a Leica 500 Real Time Kinematic (RTK) GPS. The positions of the trees were registered relative to the reference points using a Leica TPS1100 total station. Stem volume was calculated with functions by Brandel (1990) for the subsample of trees where height was field-measured. The birch volume function was used for all deciduous trees. To estimate the stem volume of all trees, linear regression models were fitted for spruce (RMSE $85.2 \mathrm{dm}^{3}(15.3 \%)$ at tree level), pine (RMSE $87.6 \mathrm{dm}^{3}(12.6 \%)$ ), and deciduous trees (RMSE $45.2 \mathrm{dm}^{3}(43.6 \%)$ ) (equation 1)

$$
\ln \left(V_{j}\right)=a_{0}+a_{1} D B H_{j}+a_{2} \ln \left(D B H_{j}\right)+\epsilon_{j}
$$

where $V_{j}$ is the stem volume of tree $j$ and $D B H_{j}$ is the DBH of tree $j$.

\subsection{Airborne Laser Scanning Data}

The acquisition of airborne laser scanning data was performed on April 24, 2007 using a helicopter-borne TopEye MKII ALS system with a wavelength of $1064 \mathrm{~nm}$. The flying altitude was $130 \mathrm{~m}$ above ground level. The first and last returns were saved for each laser pulse and the average laser return density was $30 \mathrm{~m}^{-2}$. Laser returns were classified as ground or non-ground using a progressive Triangular Irregular Network (TIN) densification method (Axelsson 2000; Axelsson 1999) implemented in the TerraScan software (Soininen 2004). The ground returns were used to derive a Digital Elevation Model (DEM) with $0.5 \mathrm{~m}$ raster cells.

\subsection{Terrestrial Laser Scanning Data}

The acquisition of TLS data was performed in September 2006 using an Optech ILRIS-3D scanner with a wavelength of $1540 \mathrm{~nm}$. The laser scanner has a $40^{\circ} \times 40^{\circ}$ field of view and the beam divergence is $170 \mu \mathrm{rad}$. One centrally located scanner position was used in each field plot. The scan density was $270 \mu \mathrm{rad}$ horizontally and vertically. Five or more trees around each scanner position were marked with velvet and registered relative to the reference points from the manual field inventory using a Leica TPS1100 total 
station. The complete $360^{\circ}$ scenes in the horizontal plane were collected by scanning one scene at a time and rotating the scanner while making sure that the scenes overlapped. One tree on the left and right edges of each scene was marked with velvet to enable rectification of the scenes. The laser reflections were rectified to create a complete point cloud for every scanner position and the laser reflections were geo-referenced using the software Polyworks (InnovMetric 2010). At least three common points were selected in each pair of scenes. The software rectified the scenes against each other pair-wise, then another scene was added and new common points selected. In a final step, all scenes were rectified simultaneously. 


\section{Methods}

\subsection{Outline}

The method developed and validated in this study is an approach to a forest inventory system based on single tree analysis of ALS data where the diameters and positions of the tree stems used as training data are derived automatically from TLS (figure 1). The method is briefly outlined here and described in detail in following sections.

The TLS data were processed by using the Hough transform (Gonzalez and Wintz 1987) to find initial estimates of the positions and diameters of the tree stems. These estimates were used as initial values to fit circles along the tree stems to estimate the DBH. The result was validated against the manual field inventory data.

The ALS data were segmented into tree crowns. For each segment, features based on the ALS data were extracted. The segments were matched with the corresponding tree stems detected from the TLS data. The heights of the trees were estimated from the ALS segments calibrated with the subsample of trees where the height was field-measured. Stem volume was then calculated using DBH estimated from TLS data and the estimated tree height. This was done both with a model based only on spruce trees as well as with a weighted model based on trees from all species. Regression models were created with the $\mathrm{DBH}$, tree height and stem volume as dependent variables and the features from the ALS segments as independent variables.

Finally, the regression models were used to estimate DBH, tree height and stem volume from ALS data. The result was matched with and validated against the manual field inventory data. The estimation of the regression models' parameters and the validation was done using leave-one-out crossvalidation for one field plot at a time. 


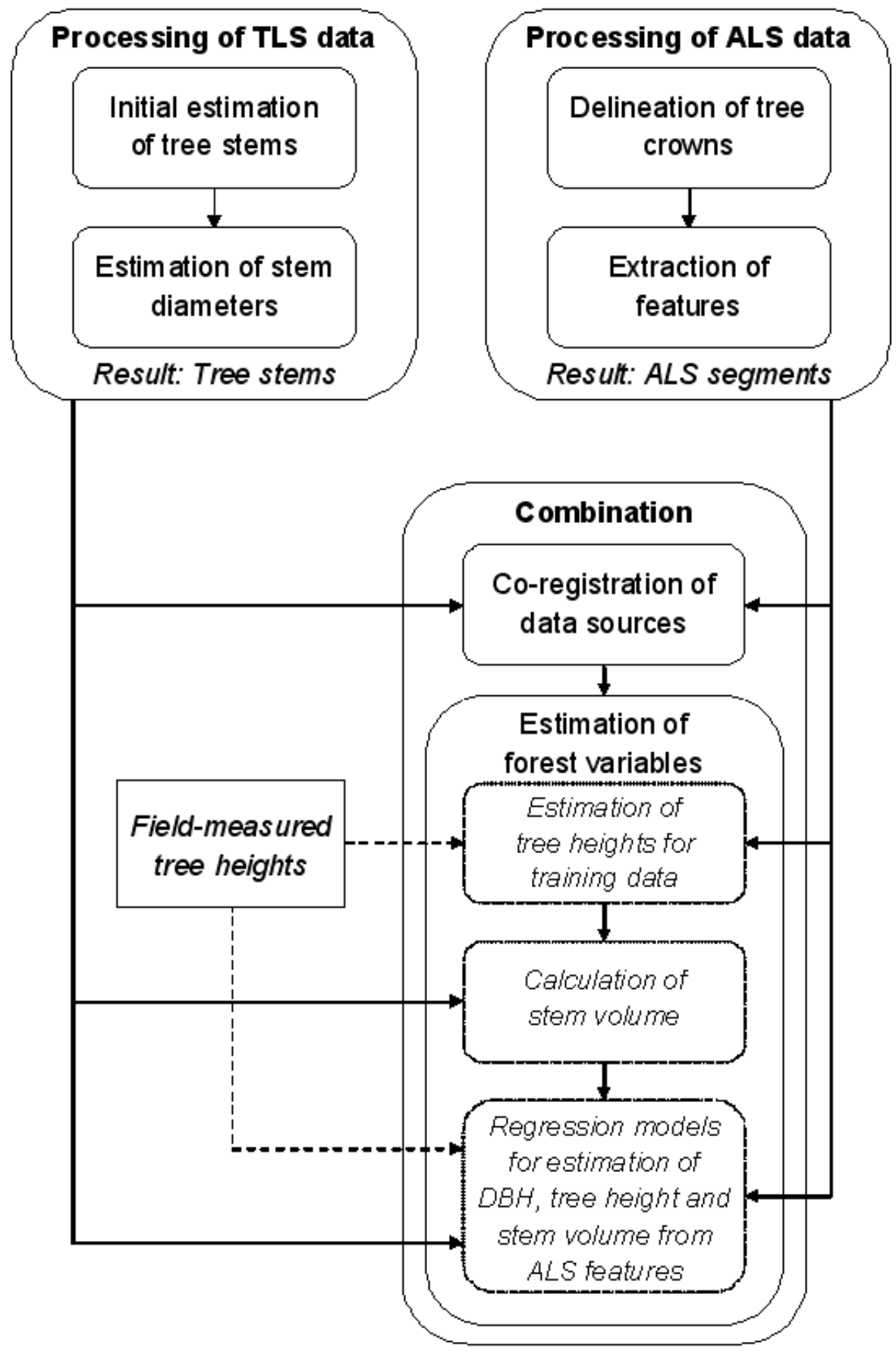

Figure 1. Outline of the method used in this study. 


\subsection{Processing of TLS data}

\subsubsection{Derivation of a DEM}

To know the height above the ground of the estimated stem diameters, a DEM must be derived from the TLS data. An algorithm was developed for this purpose. The DEM was extracted using two rasters with different cell sizes. The smaller raster cell size was $1 \mathrm{~m}$, which was the intended final DEM raster cell size. The larger raster cell size was $10 \mathrm{~m}$, which was large enough to contain laser reflections from several trees or large open ground patches. The larger raster cells had a high probability of containing a laser reflection from the ground whereas the smaller raster cells might not contain a ground reflection. In both rasters, the minimum height value was saved for each cell, giving two elevation models: one with $1 \mathrm{~m}$ raster cells and one with $10 \mathrm{~m}$ raster cells. Some cells in both rasters had missing data, which were recorded in a mask. To evaluate whether the elevation value in a smaller cell belonged to the ground or to vegetation, it was compared with the larger raster cell elevation model. At the position of the smaller raster cell, a height value was interpolated from the height values of the three closest larger neighbouring cells. These three points in 3D space defined a plane used as an approximate estimate of the height and slope of the terrain. To allow for local variations, $1 \mathrm{~m}$ was added to the interpolated height value, giving a threshold for accepting a value as ground. If the height value of the smaller raster cell was lower than this threshold, it was assumed to belong to the ground. Otherwise it was assumed that the height value belonged to vegetation and it was discarded from further calculations. At this stage, the $1 \mathrm{~m}$ raster contained ground height values and some empty raster cells with missing data. To fill the empty raster cells with estimated height values, a weighted average of the filled neighbouring raster cells was used. A cell was considered to be a neighbour if no other filled cell was in between it and the empty cell, giving free sight in a straight line. Only filled cells that existed before the fill algorithm started were considered when finding neighbours. The weight was set to the inverse cube of the distance to the cell. The end product of this process was a $1 \mathrm{~m}$ cell size DEM raster derived from the TLS data.

\subsubsection{Initial estimation of tree stems}

The algorithm used for estimating tree stems (Lindberg et al. 2010) requires initial positions and stem diameter classes as start values for the stem diameter estimation. The height value of each laser reflection in the TLS dataset was subtracted by the DEM derived from the TLS data. The coordinate system was chosen with the positive $\mathrm{z}$-axis pointing upwards and the $\mathrm{x}$ - and $\mathrm{y}$-axis in the 
horizontal plane. Stem projection images were made by projecting the laser reflections down to an image in the horizontal plane with a pixel size of $5 \mathrm{~cm}$. The pixel size was chosen to balance speed and accuracy. Initially all the pixels in the stem projection image were set to zero. A height span between 1-2 m above the ground was chosen to exclude most of the ground vegetation and the higher and denser parts of the canopies. Every laser reflection within this height span increased the pixel value of the stem projection image by one, giving high pixel values where the laser reflections were dense and low pixel values where the laser reflections were sparse. After this operation, the stem projection image contained views of the tree stems from above where most of the branches in the canopy and low ground vegetation were not visible. Tree stems in this image were shaped like arcs facing the position of the scanner (figure 2). Parts of low-positioned branches and foliage were visible as noise in the image.

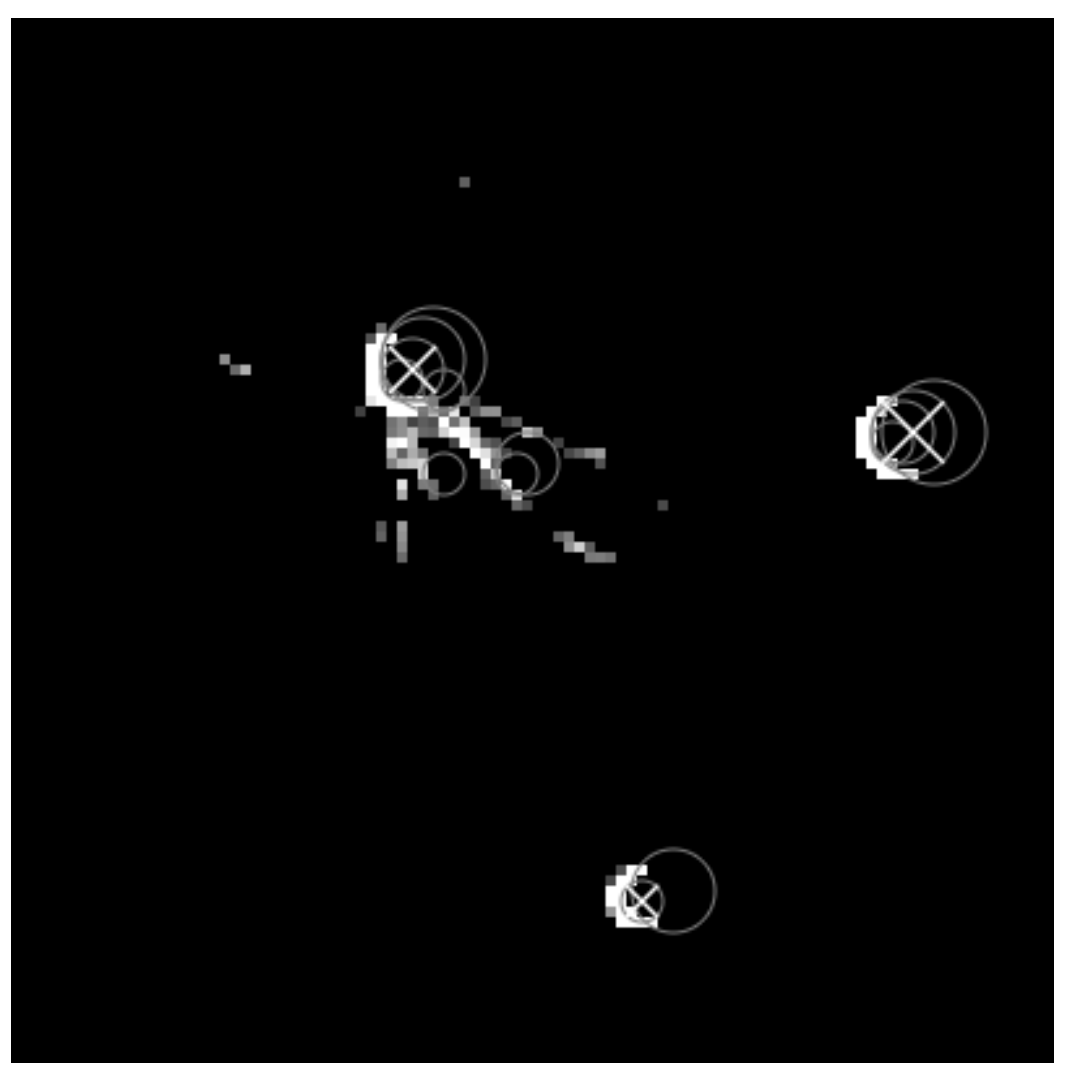

Figure 2. Image of TLS data projected to the $\mathrm{x}-\mathrm{y}$ plane shown as white and gray pixels. Gray circles are the probable tree position candidates of different diameter classes. The initial tree positions chosen by the algorithm are marked by a white $\mathrm{X}$. 
To compensate for the fact that the density of laser reflections decreases with distance from the scanner, the stem projection image was normalized by increasing the pixel values with increased distance from the scanner. To remove noise, a threshold was applied to the stem projection image before further processing.

Assuming that the tree stems were shaped like arcs facing towards the scanner in the stem projection image (figure 2), the Hough transform (Gonzalez and Wintz 1987) was used to find probable positions of the trees. This was done for a pre-chosen number of diameter classes $(20,30,40$, and 50 $\mathrm{cm})$ which were saved in different layers of a tree stem center image with a pixel size of $5 \mathrm{~cm}$.

If a pixel originated from the edge of a tree stem with the diameter of a chosen class, the possible position of the tree stem's center formed an arc with equal diameter. For this arc, the edge was facing away from the scanner. For every pixel value $>0$, an arc with this value was added to a layer in a tree stem center image (figure 3). After processing all filled pixels in the stem projection image, the positions in the tree stem center image with high pixel values had a high probability of being a stem center and positions with low pixel values had a low probability of being a stem center.

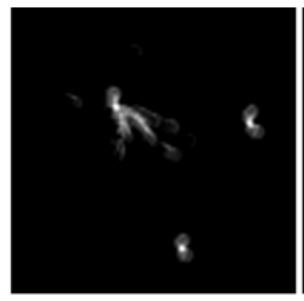

DBH $20 \mathrm{~cm}$

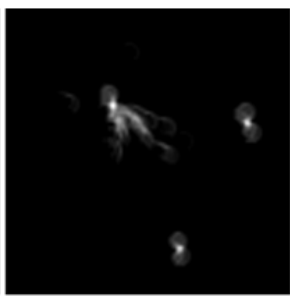

$30 \mathrm{~cm}$

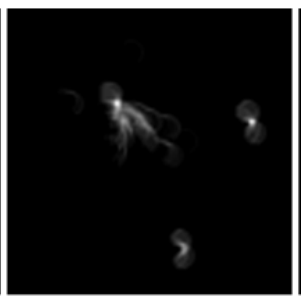

$40 \mathrm{~cm}$

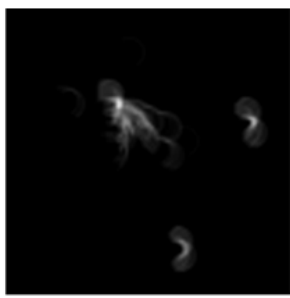

$50 \mathrm{~cm}$

Figure 3. Tree stem center images that are the Hough transform of the stem projection image (figure 2) for different diameter classes. If a stem is found, a butterfly shaped pattern is visible in the tree stem center image where the middle of the tree stem has the highest pixel value. In this image three stems are visible.

This tree stem center image contained noise that had to be removed. For instance, thick arcs gave a high probability for several diameter classes. A few single pixels with high values could also produce a probable arc, so there was a need to measure how continuous an arc was.

Thick arcs must be reduced into one diameter class. The assumption was that no pixels were filled inside the innermost diameter in the stem projection image, since the laser reflections cannot penetrate the stem of the tree. For every diameter class and position, the algorithm summed all pixel values inside 
the chosen diameter in the stem projection image, referred to as the innerRadiusSum. If this sum was large, the current diameter class was probably not the innermost diameter.

The ratio between the sum of pixels for an outer and an inner arc with opening angle $\theta$ and equal average pixel values follows equation 2 .

$$
\text { arcLengthRatio }=\frac{\theta(\text { diameterClass })}{\theta(\text { diameterClass }-2)}=\frac{\text { diameterClass }}{\text { diameterClass }-2}
$$

The value 2 in the denominator is included because the difference between two consecutive diameter classes is two pixels. This ratio was used to determine how large the innerRadiusSum would be if the inner arc was filled. In that case the innerRadiusSum of the inner arc multiplied with the arcLengthRatio would give the same value as the innerRadiusSum of the outer arc. The pixel values of positions where the diameter class was not the innermost diameter were reduced when equation 3 was applied. The factor 3 in equation 3 ensured that the average pixel value of the current diameter class had to be at least three times larger than the inner diameter class to give a positive value in the tree stem center image. In the case where the current diameter class was the innermost diameter, the pixel value was unchanged. This method also removed noise that covered a large area.

$$
\text { newValue }=\text { value }-3 \times \text { arcLengthRatio } \times \text { innerRadiusSum }
$$

To obtain a value of how continuous the arc was, a ratio between the number of pixels in an arc of that diameter class and the number of filled pixels in the current arc in the stem projection image was calculated (equation 4). This was automatically calculated for every pixel position and every diameter class in the tree stem center image.

$$
\text { shadedArcRatio }=\frac{\text { numberOfFilledPixelsInTheArc }}{\text { numberOfPixelsInTheArc }}
$$

If the arc was discontinuous, the ratio was lower than one, which reduced the pixel value even further (equation 5).

$$
\text { newModifiedValue }=\text { shadedArcRatio } \times \text { newValue }
$$

Once the noise was reduced, the modified pixel values for each diameter class were saved in the tree stem center image. All negative values were set to zero.

For every diameter class, a watershed algorithm was applied to the tree stem center image giving local pixel value maxima. For continuous areas with 
equal pixel values, only the centermost pixel position was saved. Every local maximum position for all diameter classes was considered to be a probable stem center. If two tree stem positions were within each other's radii, they were considered to be candidates to the same position. Several trees could be linked in this way as a group of candidates. To find the most probable tree stem position and diameter, the candidate with the highest pixel value in the tree stem center image was chosen. If several trees had the same pixel value, the largest tree was chosen. The chosen tree stem positions and diameter classes were used as initial estimates for the final estimation of stem positions and diameters.

\subsubsection{Estimation of stem diameters}

Diameters were estimated along each stem by fitting circles in two steps. In the first step, the resulting position and diameter from the initial estimation were used to select a set of laser reflections, and circles were then fitted to the laser reflections in horizontal slices. In the second step, the position and diameter of the fitted circles from the first step were used to select a new set of laser reflections and new circles were fitted to those laser reflections (figure 4 and 5). This is similar to fitting cylinders along the stem (Thies et al. 2004) although the second step was added to make the estimation less sensitive to the local influence of branches.
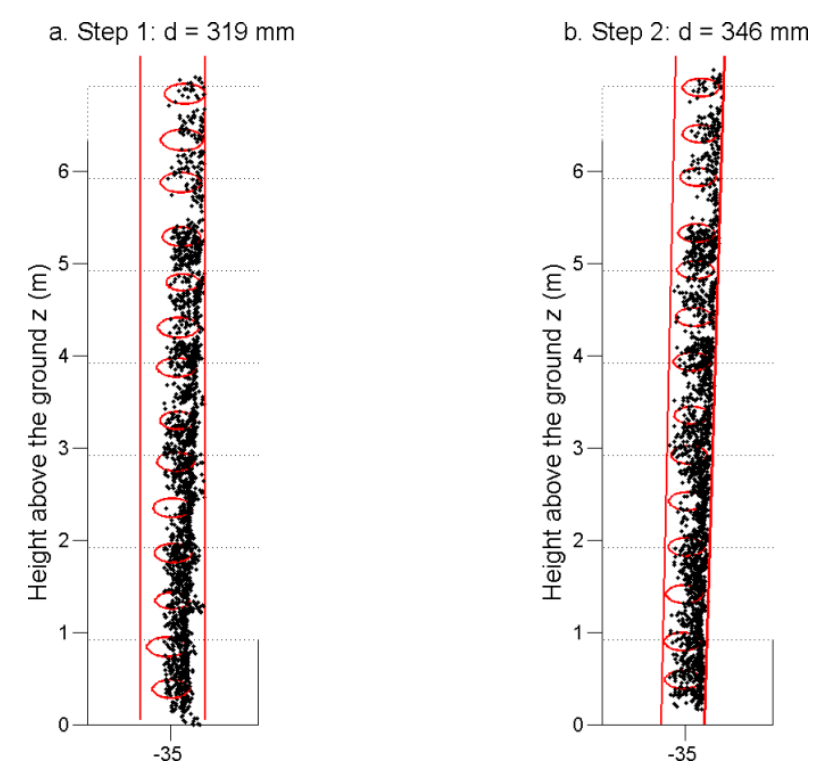

Figure 4. Laser reflections selected in the first step (a) and the second step (b) for one tree stem shown in three dimensions. The vertical lines are the limits for selecting laser reflections in the respective steps and the horizontal circles are the result of the estimation in the respective steps. 
a. Step 1: $\mathrm{d}=319 \mathrm{~mm}$

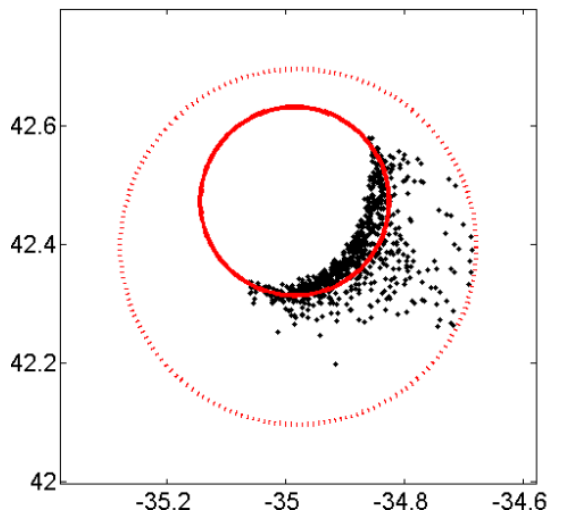

b. Step 2: $\mathrm{d}=346 \mathrm{~mm}$

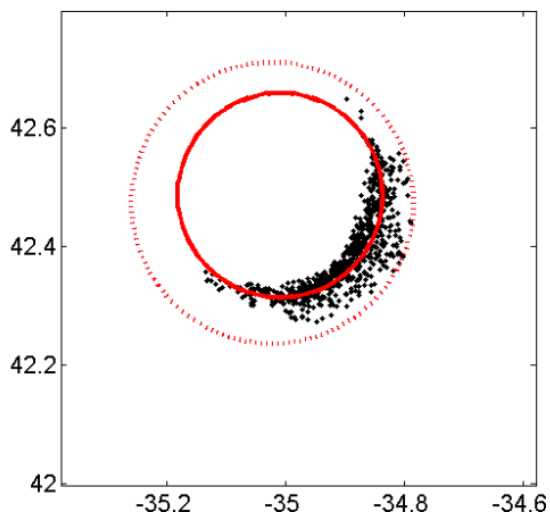

Figure 5. Laser reflections in a horizontal slice of $50 \mathrm{~cm}$ height centered around $1.3 \mathrm{~m}$ above the ground selected in the first step (a) and the second step (b) for one tree stem shown in two dimensions. The dotted circles are the limits for selecting laser reflections in the respective steps and the solid circles are the result of the estimation at $1.3 \mathrm{~m}$ above the ground in the respective steps.

In the first step, all laser reflections that fulfilled equation 6 were selected

$$
\left(x_{i}-c_{x, i n i t}\right)^{2}+\left(y_{i}-c_{y, \text { init }}\right)^{2} \leq\left(1.5 \times \frac{d_{\text {init }}}{2}\right)^{2}
$$

where $\left(c_{x, \text { init }}, c_{y, \text { init }}\right)$ is the midpoint of the stem and $d_{\text {init }}$ is the stem diameter given by the initial estimation from the Hough transform.

The laser reflections were divided into horizontal slices, each with a height of $50 \mathrm{~cm}$. For each slice, a circle was fitted (equation 7).

$$
\left(\frac{d}{2}\right)^{2}=\left(x_{i}-c_{x}\right)^{2}+\left(y_{i}-c_{y}\right)^{2}
$$

This was done by minimizing the sum of squared errors, $E$ (equation 8 ),

$$
E=\sum_{i=1}^{n}\left(\sqrt{\left(x_{i}-c_{x}\right)^{2}+\left(y_{i}-c_{y}\right)^{2}}-\frac{d}{2}\right)^{2}
$$

numerically by trying combinations of $d, c_{x}$ and $c_{y}$ (equations 9-11) 


$$
\begin{aligned}
& d=d_{0} \times(1 \pm S \times 0.1 \times k), k=1,2, . ., 10 \\
& c_{x}=c_{x, 0} \pm \frac{d_{0}}{2} \times S \times 0.1 \times k, k=1,2, . ., 10 \\
& c_{y}=c_{y, 0} \pm \frac{d_{0}}{2} \times S \times 0.1 \times k, k=1,2, . ., 10
\end{aligned}
$$

where $S$ and $k$ are unit-less. The initial values of $d_{0}, c_{x, 0}$ and $c_{y, 0}$ were set to those given by the initial estimation. The search ratio $S$ was initially set to $S=$ 5 and the combination of $d, c_{x}$ and $c_{y}$ with the smallest $E$ was chosen. The search ratio was then divided by two, and new combinations of $d, c_{x}$ and $c_{y}$ were tried with $d_{0}, c_{x, 0}$ and $c_{y, 0}$ set to the chosen values from the previous search ratio. This was repeated three times to estimate $d, c_{x}$ and $c_{y}$ for each slice.

The maximum value of the stem diameter of the lowest horizontal slice was based on the stem diameter given by the initial estimation (equation 12).

$$
d_{\max }=2 \times d_{\text {init }}
$$

For subsequent slices, maximum values of the stem diameter were based on the mean value $\bar{d}$ of the stem diameters estimated for the lower slices (equation 13).

$$
d \leq \begin{cases}2 \times \bar{d} & \text { if } 2 \times \bar{d} \leq d_{\max } \\ d_{\max } & \text { if } 2 \times \bar{d}>d_{\max }\end{cases}
$$

In this way, circles with $d, c_{x}$ and $c_{y}$ were fitted along the whole stem.

The dependencies between the height above the ground, $z$, and the estimated values of $d, c_{x}$ and $c_{y}$, respectively, were approximated as linear functions $d(z), c_{x}(z)$ and $c_{y}(z)$ using linear regression. The initial values for the second step were $d(z), c_{x}(z)$ and $c_{y}(z)$ as estimated from the first step. In the second step, all laser reflections that fulfilled equation 14 were selected.

$$
\left(x_{i}-c_{x}\left(z_{i}\right)\right)^{2}+\left(y_{i}-c_{y}\left(z_{i}\right)\right)^{2} \leq\left(1.2 \times \frac{d\left(z_{i}\right)}{2}\right)^{2}
$$

If less than 1000 laser reflections fulfilled the criterion, $d(z)$ was increased by $1 / 10$ of the original value and a new set of laser reflections was selected. This was repeated until at least 1000 laser reflections fulfilled the criterion.

The laser reflections were divided into horizontal slices and circles were fitted as in the first step. S was initially set to 1 . The maximum value of the stem diameter of the lowest horizontal slice was based on the stem diameter 
estimated in the first step and the minimum distance, $D_{\min }$, between the laser reflections $0-10 \mathrm{~m}$ behind the tree stem (equation 15).

$$
d_{\max }= \begin{cases}\overline{d(z)} & \text { if } D_{\min }<\overline{d(z)} \\ D_{\min } & \text { if } \overline{d(z)} \leq D_{\min } \leq 1.2 \times \overline{d(z)} \\ 1.2 \times \overline{d(z)} & \text { if } D_{\min }>1.2 \times \overline{d(z)}\end{cases}
$$

For subsequent slices, maximum values of the stem diameter were computed from equation 13. Finally, the dependency between the height above the ground $z$ and the stem diameter $d$ was approximated as a linear function with linear regression. The function was used to estimate the stem diameter at $1.3 \mathrm{~m}$ above the ground (i.e., the DBH).

Some factors that may affect the accuracy of the estimates are the distance from the scanner, the number of laser reflections from the tree stem, the residual of the fitted circle, and if the tree stem is partly hidden behind another object. The last factor can be determined when all the tree stems visible from the scanner in one field plot are estimated and the circle sectors hidden behind the tree stems can be derived. Based on a combination of these factors, it is possible to determine conditions to include or exclude a tree stem in the training data.

To reduce the number of tree stems for which the estimation had a great risk of being inaccurate, the training data included only tree stems $\leq 40 \mathrm{~m}$ from the scanner (case II in the Results section) and with a set of laser reflections with width $\geq 0.5 \times d$ and $\leq 1.5 \times d$ (figure 6 ) (case III in the Results section). The restrictions were empirically based on the accuracy of the DBH estimates.
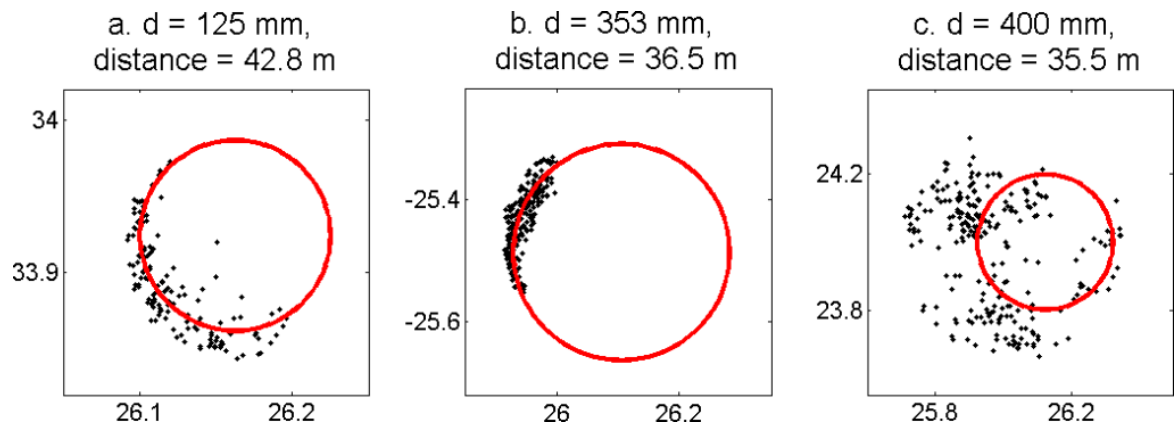

Figure 6. Examples of sets of laser reflections and fitted circles. (a) Width $\geq 0.5 \times d$ and $\leq 1.5 \times d$, (b) width $<0.5 \times d$, and (c) width $>1.5 \times d$. 


\subsection{Processing of ALS data}

\subsubsection{Delineation of tree crowns}

The segmentation method used for tree crown delineation was based on geometric tree crown models (Holmgren et al. 2010) and rasters with $0.25 \mathrm{~m}$ cells. A canopy height model (CHM) was first created. A correlation surface (CS) was then calculated where a raster cell value was set to the maximum correlation found using tests with geometric tree models having the origin placed at the centre of the raster cell. For each raster cell, different geometric models (i.e., generalized ellipsoids; Pollock 1996) were used to calculate the height of the model surface (h). The correlation was then calculated between $\mathrm{z}$ values of laser returns and h-values calculated for the $\mathrm{x}$ - and $\mathrm{y}$-values of the laser returns. The model height was set to the value of the CHM and different values of the radius $r_{G E R}$ were tested, namely $r_{G E R}=0.5 \mathrm{~m}, 0.7 \mathrm{~m}$, and $r_{\max }$, where $r_{\max }$ was the maximum expected radius set as a proportion of model height. The CS was smoothed 3 times with a $3 \times 3$ Gaussian filter and then used for the segmentation. To do this, a starting point (i.e., a seed) was placed in each raster cell with a non-zero CHM value and with a positive CS value. For each seed, the current location was updated to the neighbouring cell with the highest value of the smoothed CS and this was repeated until the position could not be updated because a local maximum of the smoothed CS had been reached. The seeds with the same final local maximum defined a segment. The next step was to merge segments with the aim of removing segments that only covered part of a tree crown. For each segment, geometric models were used to decide if the segment should be merged or not to a neighbouring segment. The model origin was placed in the raster cell having the maximum value of the CS within the tested segment (i.e., the segment centre) and a test value was calculated using only laser data within that segment. The model was also placed at a neighbouring segment centre and a test value was calculated using only laser data from within the tested segment. If the test at the tested segment centre yielded a higher value than a test at any neighbouring segment centre, the segment was not merged; otherwise, the segment was merged with the neighbouring segment for which the highest test value was calculated. The test value was the weighted correlation between z-values of the laser returns and hvalues calculated for the $\mathrm{x}$ - and $\mathrm{y}$-values of the laser returns, where the weight was distance above ground level multiplied by a penalty factor that was a function of the difference between the predicted and observed ratio of radius to model height. In this study, classes of the value obtained by dividing the standard deviation with the laser-derived maximum height within a segment were used to predict the ratio of radius to model height. In a training phase 
where the tree positions were known on field plots, different ratios were tested. For each class, the ratio that yielded the highest proportion of one tree within a segment was chosen and then used in the prediction phase.

\subsubsection{Extraction of features}

The maximum height value $\left(H_{A L S}\right)$ of the CHM within the segment was used for estimation of tree height. The 10th, 20th, ... percentile of laser returns inside the segment $\left(p_{10}, p_{20}, ..\right)$ were derived. The crown area of an individual tree was derived by counting the number of raster cells in a segment and the width $\left(W_{A L S}\right)$ of a segment was then derived assuming that a tree crown was circular.

\subsection{Combination of ALS and TLS data}

\subsubsection{Co-registration of data sources}

To co-register the ground measurements with aerial data, the position image method by Olofsson et al. (2008) was further developed. In the original method, two tree list-datasets with tree positions and size parameters were coregistered by cross-correlating position images and linking the trees with the smallest treetop distance. However, TLS data from an area with trees have zones that are obscured from the scanner, which complicates automatic coregistration between tree positions found in the TLS and ALS data. The obscured zones were therefore masked from the field plot depending on where tree stems were found in the TLS data; only the parts of the field plot visible from the terrestrial laser scanner were used for correlation. The tree linking algorithm was the same as in (Olofsson et al. 2008).

\subsubsection{Estimation of forest variables}

$\mathrm{DBH}$, tree height and stem volume were estimated with regression models from the ALS segments. The parameters of the regression models were estimated using training data derived from TLS data and also, as a comparison, using training data from the manual field inventory. The result was two different sets of estimated parameters for each regression model. The training data derived from the TLS data included tree stems $\leq 40 \mathrm{~m}$ from the scanner and a set of laser reflections with width $\geq 0.5 \times d$ and $\leq 1.5 \times d$. The training data from the manual field inventory included tree stems in a circle $\leq 40 \mathrm{~m}$ from the centre of the field plot to make co-registration with ALS data possible (Olofsson et al. 2008). 
The following regression model was used to estimate the DBH of tree $j$ (equation 16)

$$
\ln \left(D B H_{j}\right)=\alpha_{0}+\alpha_{1} \ln \left(H_{A L S, j}\right)+\alpha_{2} \ln \left(W_{A L S, j}\right)+\alpha_{3} \ln \left(p_{70, j}\right)+\epsilon_{j}
$$

where $D B H_{j}$ is the field-measured DBH (from TLS data or caliper) of tree $j$, $H_{A L S, j}$ is the height of the ALS segment, $W_{A L S, j}$ is the width of the ALS segment, and $p_{70, j}$ is the 70th percentile of laser returns inside the segment. All variables in the model had a $p$-value $\leq 0.001$ and the variance inflation factor (VIF) was $\leq 3.5$. The estimates were corrected for logarithmic bias (Holm 1977).

The following regression model was used to estimate the height of tree $j$ (equation 17)

$$
H_{j}=\beta_{0}+\beta_{1} H_{A L S, j}+\epsilon_{j}
$$

where $H_{j}$ is the field-measured height of tree $j$. The p-value was $\leq 0.001$. The regression models for the tree height were based on the subsample of trees where the height was measured in field. For the trees detected from TLS data, the tree height of the closest manually measured tree within $0.5 \mathrm{~m}$ was chosen.

The stem volume was calculated from the DBH, estimated from TLS data or measured with a caliper, and the tree height estimated from the ALS data (Brandel 1990). The following regression model was used to estimate the stem volume of tree $j$ (equation 18)

$$
\ln \left(V_{j}\right)=\gamma_{0}+\gamma_{1} \ln \left(H_{A L S, j}\right)+\gamma_{2} \ln \left(W_{A L S, j}\right)+\gamma_{3} \ln \left(p_{70, j}\right)+\epsilon_{j}
$$

where $V_{j}$ is the field-measured stem volume of tree $j$. All variables in the model had a $p$-value $\leq 0.002$ and the VIF was $\leq 3.5$. The estimates were corrected for logarithmic bias (Holm 1977). For the trees detected from the TLS data, two different regression models were used to estimate stem volume. One model was based on spruce trees only and one model was based on all tree species. The volume of the latter model was calculated as a weighted mean of the stem volume for each tree species (pine, spruce and deciduous) with the same DBH and height, where the weights were proportional to the stem volume of each tree species in the training data. 


\subsection{Validation}

The root mean square error (RMSE) and bias were calculated for the estimated $\mathrm{DBH}$, tree height and stem volume at tree level. The RMSE and bias for DBH were calculated as follows (equations 19-20) (corresponding expressions were used for tree height and stem volume)

$$
\begin{aligned}
& R M S E=\sqrt{\frac{\sum_{j=1}^{n}\left(D \hat{B} H_{j}-D B H_{j}\right)^{2}}{n}} \\
& \text { bias }=\frac{\sum_{j=1}^{n}\left(D \hat{B} H_{j}-D B H_{j}\right)}{n}
\end{aligned}
$$

where $D B H_{j}$ is the manually measured and $D \hat{B} H_{j}$ is the estimated DBH of tree $j$ and $n$ is the total number of trees.

This was done to validate the result of the estimation of DBH from TLS data and the result of the estimation of $\mathrm{DBH}$, tree height and stem volume from ALS data trained with TLS data as well as with data from the manual field inventory.

The DBH estimated from TLS data was validated against the closest manually measured tree within $0.5 \mathrm{~m}$ from the tree detected from TLS data. If the manually measured tree had a neighbour within $0.5 \mathrm{~m}$, the tree was excluded from the validation.

The estimates from ALS data were validated using leave-one-out crossvalidation. One field plot at a time was excluded from the dataset and the rest of the dataset was used as training data to estimate forest variables for the excluded field plot. The validation data were manually measured tree stems in a circle $\leq 40 \mathrm{~m}$ from the centre of the respective field plots to make coregistration with ALS data possible (Olofsson et al. 2008). The tree height was validated only for the subsample of trees where the height was measured in field. The stem volume was validated only for spruce trees since two of the models were based only on spruce trees and the volume functions are species specific. The stem volume was validated against the stem volume from the manual field inventory. 


\section{Results}

\subsection{Estimation of DBH from TLS data}

The RMSE of the DBH estimated from the TLS data (table 2 and figure 7) was lower when excluding trees more than $40 \mathrm{~m}$ from the scanner (II) and when excluding trees with an estimated diameter which was not realistic compared to the set of laser reflections (III). The lowest RMSE was achieved when both of these restrictions were imposed (IV).

Table 2. RMSE and bias of DBH estimated from TLS data and validated against manual field measurements. Case I: All tree stems inside $80 \times 80 \mathrm{~m}$ field plots; Case II: Tree stems $\leq 40 \mathrm{~m}$ from the scanner; Case III: Tree stems with a set of TLS reflections with width $\geq 0.5 \times d$ and $\leq 1.5 \times d$; Case IV: Restrictions from II and III.

\begin{tabular}{|c|c|c|c|c|c|c|c|c|}
\hline & $\begin{array}{l}\text { Number } \\
\text { of } \\
\text { manually } \\
\text { measure } \\
d \text { trees }\end{array}$ & $\begin{array}{l}\text { Number } \\
\text { of trees } \\
\text { found } \\
\text { from } \\
\text { TLS data }\end{array}$ & $\begin{array}{l}\text { Number } \\
\text { of trees } \\
\text { found } \\
\text { from } \\
\text { TLS data } \\
\text { with } \\
\text { manually } \\
\text { measure } \\
\text { d tree }\end{array}$ & $\begin{array}{l}\text { Mean } \\
\text { DBH } \\
(\mathrm{mm})\end{array}$ & RMSE & $\%$ & $(\mathrm{~mm})$ & $\%$ \\
\hline I & 2276 & 1324 & 1032 & 290.7 & 38.0 & 13.1 & 1.6 & 0.5 \\
\hline II & 1832 & 1133 & 899 & 289.8 & 35.9 & 12.4 & 2.5 & 0.9 \\
\hline III & 2276 & 1274 & 1005 & 292.2 & 34.4 & 11.9 & -0.2 & -0.1 \\
\hline IV & 1832 & 1075 & 876 & 291.1 & 32.1 & 11.0 & 0.8 & 0.3 \\
\hline
\end{tabular}




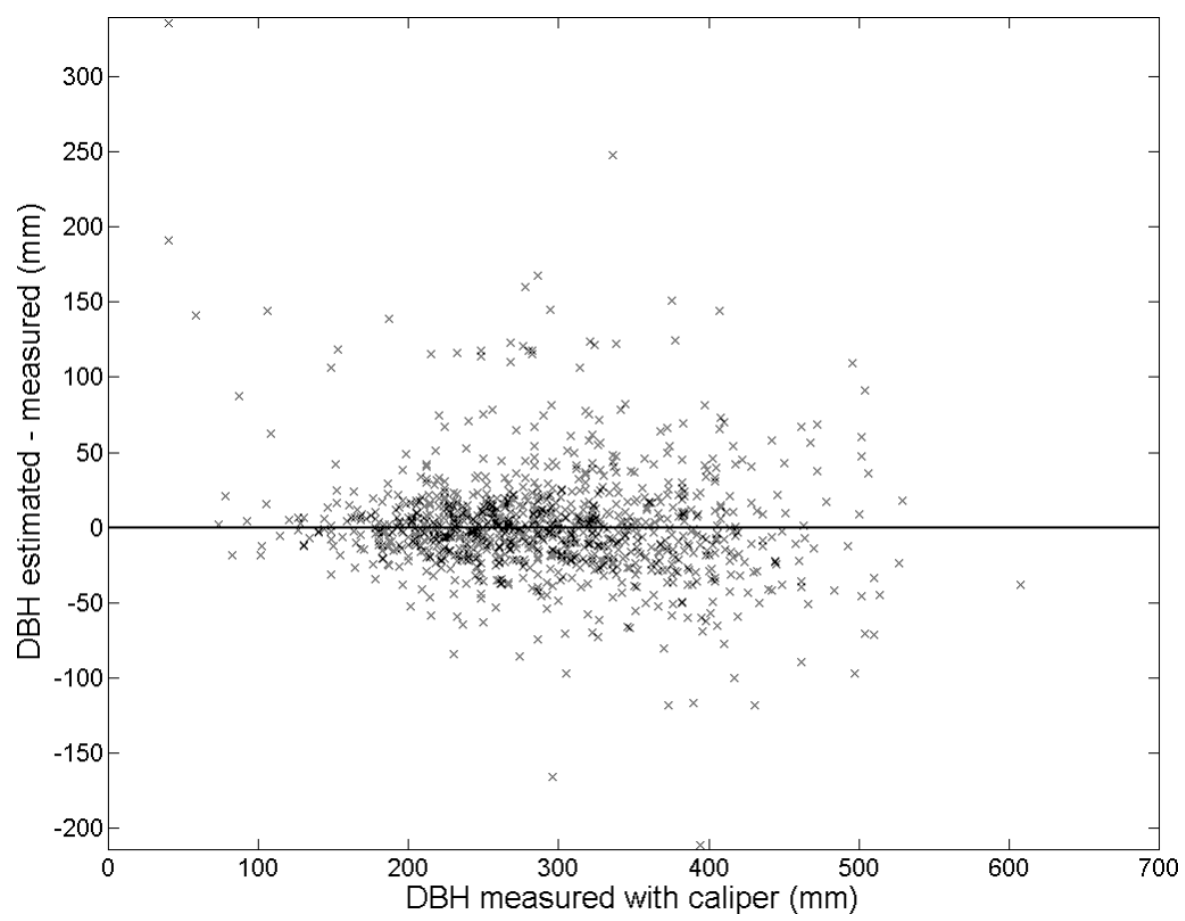

Figure 7. The residuals of DBH estimated from TLS data versus manually measured DBH for all tree stems (I in table 2).

The RMSE and bias of DBH estimated from the TLS data varied for different tree species. RMSE was largest for spruce and smallest for deciduous trees (table 3).

Table 3. RMSE and bias of DBH estimated from TLS data per tree species. Case I: All tree stems; Case II: Tree stems $\leq 40 \mathrm{~m}$ from the scanner; Case III: Tree stems with a set of TLS reflections with width $\geq 0.5 \times d$ and $\leq 1.5 \times d$; Case IV: Restrictions from II and III.

\begin{tabular}{lllllll}
\hline & Pine & \multicolumn{3}{l}{ Spruce } & \multicolumn{2}{c}{ Deciduous } \\
\cline { 2 - 7 } & RMSE \% & Bias \% & RMSE \% & Bias \% & RMSE \% & Bias \% \\
\hline I & 12.4 & -1.4 & 13.2 & 0.6 & 6.8 & -1.6 \\
II & 12.8 & 0.0 & 12.4 & 0.9 & 6.8 & -1.4 \\
III & 10.3 & -2.7 & 11.8 & 0.0 & 6.7 & -1.6 \\
IV & 10.3 & -1.5 & 11.0 & 0.3 & 6.8 & -1.4 \\
\hline
\end{tabular}




\subsection{Combination of ALS and TLS data}

A greater proportion of trees detected from TLS data with large diameters could be linked to tree crowns delineated from ALS data as compared to trees with small diameters detected from TLS data. The mean DBH of all spruce trees detected from TLS data was $295.4 \mathrm{~mm}$ and the bias was $0.9 \mathrm{~mm}$. The mean DBH of the spruce trees detected from TLS data that could be connected to tree crown segments in ALS data was $305.0 \mathrm{~mm}$ and the bias was $2.1 \mathrm{~mm}$ (figure 8). The mean DBH of the spruce trees detected from TLS data that could not be connected to tree crown segments in ALS data was $205.0 \mathrm{~mm}$ and the bias was $-9.8 \mathrm{~mm}$.

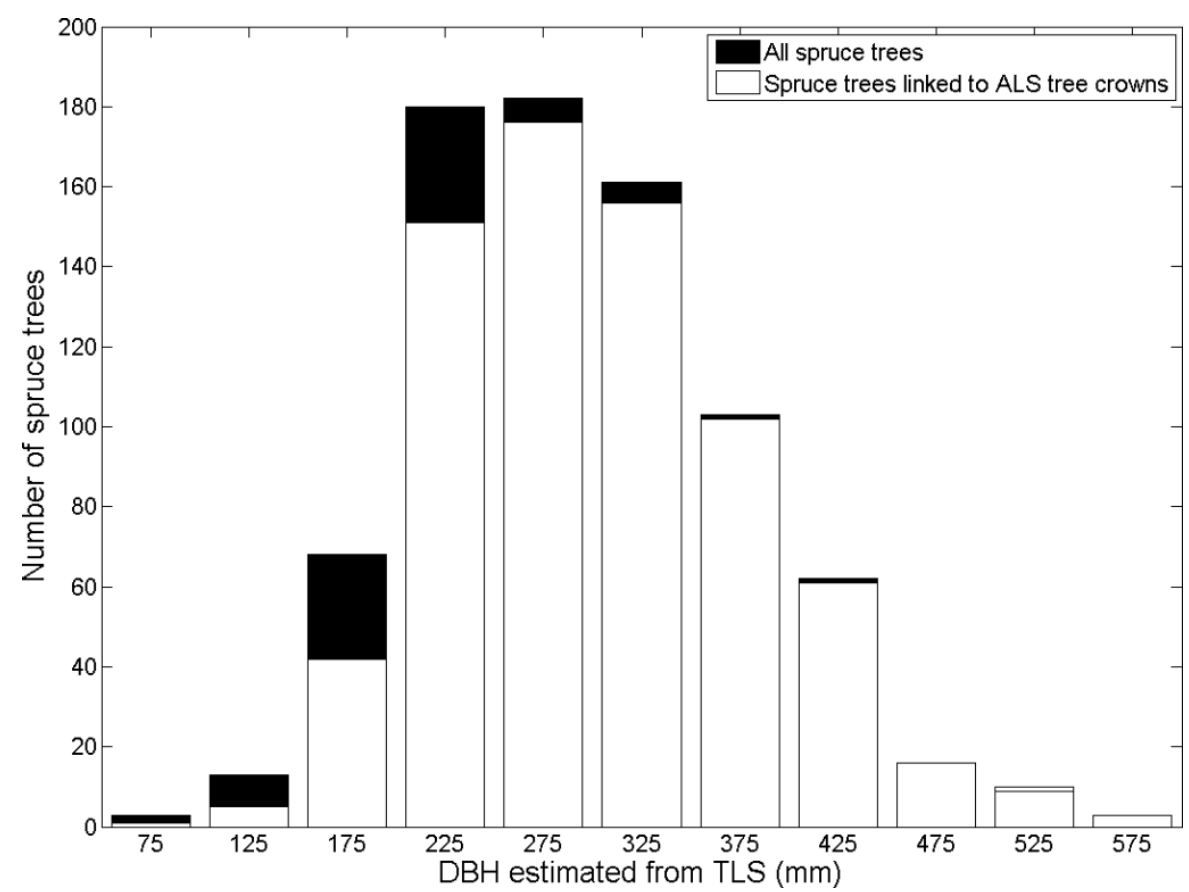

Figure 8. The distribution of DBH for all spruce trees found from TLS data and the distribution of DBH for the subset of spruce trees found from TLS data that were used as training data.

The RMSE and bias at tree level with trees detected from TLS data as training data were almost as low as when trees from the manual field inventory were used as training data (table 4 and figures 9-11). The training data included only tree stems that fulfilled restriction IV in table 2 . The validation of the estimates from ALS data was done for the same trees for both sets of training data. The figures $9 \mathrm{c}, 10 \mathrm{c}$, and $11 \mathrm{c}$ show the difference between the estimates with different training datasets versus the mean of the estimates with different 
training datasets (Bland and Altman 1986). For DBH, the estimation with TLS data as training data resulted in a larger overestimation for small values and a larger underestimation for large values (i.e., the regression model with manual field inventory as training data fitted better; figure 9c). For tree height, the difference was very small between the estimates with different training datasets (figure 10c). The linear trends are due to the pair-wise differences between the linear models in the different field plots, which are results of the crossvalidation. For stem volume, the best result was achieved with trees detected from TLS data as training data and a weighted model based on all tree species (figure 11c).

Table 4. $D B H^{1}$ (equation 16), tree height ${ }^{2}$ (equation 17), and stem volume (equation 18) estimated from ALS data with trees found from TLS data as training data and trees from the manual field inventory as training data.

\begin{tabular}{|c|c|c|c|c|c|}
\hline Training data & $\begin{array}{l}\text { Number of } \\
\text { trees in } \\
\text { training } \\
\text { data }\end{array}$ & RMSE & Bias & RMSE & Bias \\
\hline $\mathrm{DBH}$ & & $(\mathrm{mm})$ & $\%$ & $(\mathrm{~mm})$ & $\%$ \\
\hline TLS data & 933 & 46.0 & 15.4 & -1.0 & -0.3 \\
\hline Manual field inventory & 1508 & 45.1 & 15.1 & 0.4 & 0.1 \\
\hline Tree height & & $(\mathrm{dm})$ & $\%$ & $(\mathrm{dm})$ & $\%$ \\
\hline TLS data & 85 & 9.4 & 3.7 & 0.4 & 0.2 \\
\hline Manual field inventory & 142 & 9.2 & 3.6 & -0.2 & -0.1 \\
\hline Stem volume & & $\left(\mathrm{dm}^{3}\right)$ & $\%$ & $\left(\mathrm{dm}^{3}\right)$ & $\%$ \\
\hline $\begin{array}{l}\text { TLS data, model based } \\
\text { only on spruce trees }\end{array}$ & 723 & 200.4 & 34.6 & 39.7 & 6.8 \\
\hline $\begin{array}{l}\text { TLS data, weighted } \\
\text { model based on trees } \\
\text { from all species }\end{array}$ & 933 & 197.4 & 34.0 & 19.8 & 3.4 \\
\hline $\begin{array}{l}\text { Manual field inventory, } \\
\text { model based only on } \\
\text { spruce trees }\end{array}$ & 1411 & 200.2 & 34.5 & 27.4 & 4.7 \\
\hline
\end{tabular}

1. The DBH was validated for manually measured trees in a circle $\leq 40 \mathrm{~m}$ from the centre of the respective field plots.

2. The tree height was validated for manually height measured trees in a circle $\leq 40 \mathrm{~m}$ from the centre of the respective field plots.

3. The stem volume was validated for manually measured trees in a circle $\leq 40 \mathrm{~m}$ from the centre of the respective field plots. The stem volume was validated only for spruce trees since two of the models were based only on spruce trees. 

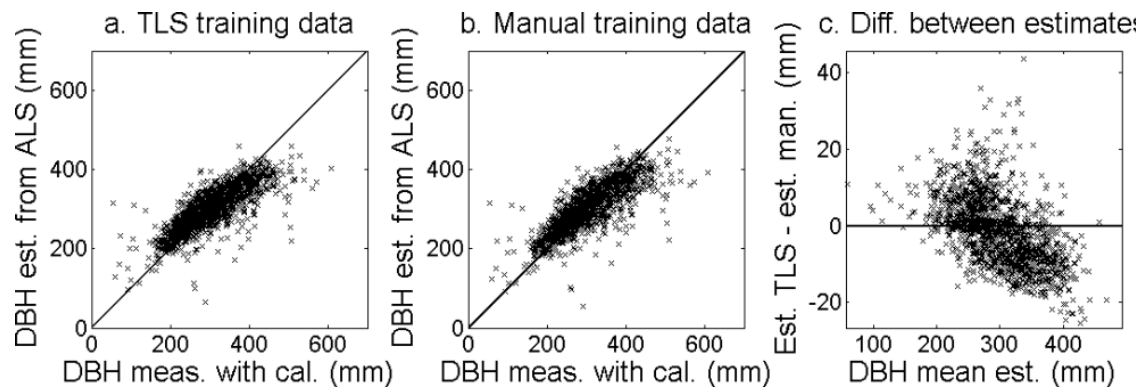

Figure 9. (a) DBH estimated from ALS data when trained with DBH estimated from TLS data, with a 1:1 line, (b) DBH estimated from ALS data when trained with DBH from the manual field inventory, with a 1:1 line, and (c) the difference between DBH estimates when trained with TLS data and DBH estimates when trained with manual field inventory data versus the mean of DBH estimates when trained with TLS data and DBH estimates when trained with manual field inventory data.
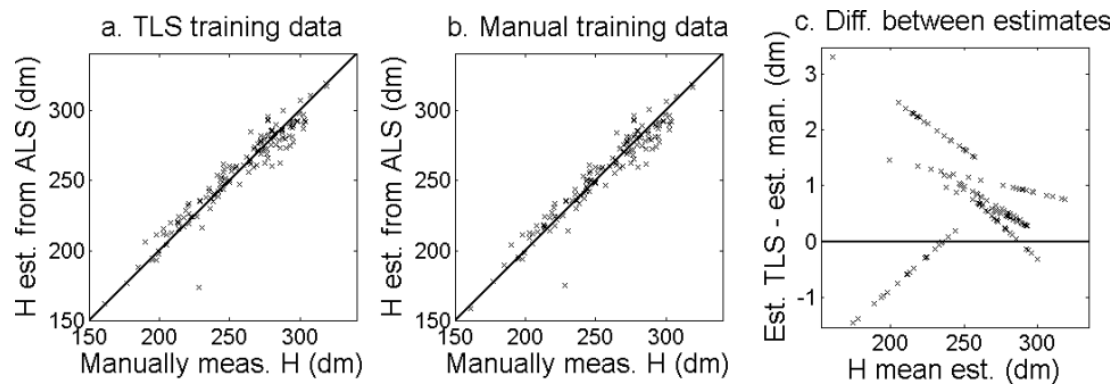

Figure 10. (a) $\mathrm{H}$ estimated from ALS data when trained with $\mathrm{H}$ of trees found from TLS data, with a 1:1 line, (b) $\mathrm{H}$ estimated from ALS data when trained with $\mathrm{H}$ of trees from the manual field inventory, with a 1:1 line, and (c) the difference between $\mathrm{H}$ estimates when trained with TLS data and $\mathrm{H}$ estimates when trained with manual field inventory data versus the mean of $\mathrm{H}$ estimates when trained with TLS data and H estimates when trained with manual field inventory data.
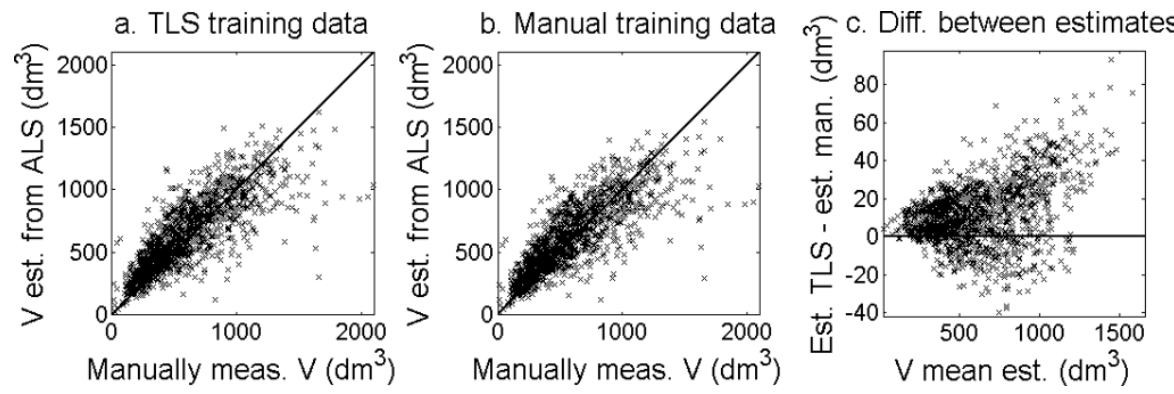

Figure 11. (a) Stem volume estimated from ALS data when trained with stem volume of trees found from TLS data, with a 1:1 line, (b) stem volume estimated from ALS data when trained with stem volume of trees from the manual field inventory, with a 1:1 line, and (c) the difference between stem volume estimates when trained with TLS data and stem volume estimates when trained with manual field inventory data versus the mean of stem volume estimates when trained with TLS data and stem volume estimates when trained with manual field inventory data. 


\section{Discussion}

This study has presented a new method to combine TLS and ALS data for forest inventory at the single tree level. The method uses tree stems detected from TLS data as training data for tree crown segments from ALS data. The only manual measurements needed are the heights of a subsample of trees in each field plot to calibrate the tree heights estimated from ALS data. This reduces the need for manual field measurements, which means that a field inventory could be done more efficiently and with smaller risk for human errors.

Validation of DBH estimation from TLS data has been done for larger samples (i.e., more than 10-20 trees) in only a few other studies. The accuracy of the DBH estimated from TLS data achieved in our study was better than in a study based on time of flight TLS data collected in a pine forest (Hopkinson et al. 2004) and worse than in a study based on phase shift TLS data collected in a mixed forest (Maas et al. 2008). Both the cited studies were based on TLS data collected at multiple positions.

We improved the DBH estimates slightly by only using tree stems within 40 $\mathrm{m}$ from the scanner. The maximum distance depends on the forest type and might be shorter in a multi-story forest with dense shrubs. However, the accuracy of DBH estimated from TLS data in this study was not highly dependent of the distance from the scanner. This may be related to the limited vertical field of view of the used scanner. For trees close to the scanner, the scanner only measures the lowest part of the tree stems. For trees further away from the scanner, the scanner measures a longer part of the tree stems but the tree stems may be obscured by stems and branches from other trees. By using a terrestrial laser scanner that measures distances within a larger vertical field of view, it might be possible to achieve higher accuracy for trees close to the scanner.

The RMSE of the estimated DBH was larger for spruce trees than for pine trees, which is probably due to denser branches in spruce forest. Noise 
reduction is essential to select the laser reflections from a tree stem before estimating the diameter.

When taken from an area with trees, TLS data will have zones that are obscured from the scanner, meaning that some trees will be completely hidden and some trees will be partly hidden. One solution to this problem is to collect TLS data at multiple positions. However, in that case, criteria would still be needed to verify that the measurement of every tree stem is accurate enough. To achieve this it is useful to estimate the accuracy of the estimated DBH directly from the laser reflections. The accuracy criteria depend on the scanner and also on the forest type. In this study, the accuracy of the DBH estimated from TLS data was highest for tree stems with a set of laser reflections with width $\geq 0.5 \times d$ and $\leq 1.5 \times d$, where $d$ is the estimated stem diameter. One advantage of using trees detected from TLS data as training data for ALS data estimates at single tree level is that it is not necessary to measure all trees as long as the selected tree stems are representative for the forest.

The tree heights could also be estimated from the TLS data. However, the laser scanner used in this study had a limited vertical field of view and very few tree tops were visible in the data. In general, the error of such estimation is typically 1-10 m (Maas et al. 2008; Hopkinson et al. 2004). The RMSE of tree height estimated from ALS data is typically less than $1 \mathrm{~m}$ (Persson et al. 2002) which means that the training data would have much larger errors than the estimate. To determine the positions of trees with manually measured heights from the TLS data, the trees could be marked with numbers made from material that is clearly visible in the TLS data and can be identified during the analysis.

The combination of TLS data with remote sensing data requires coregistration of the data sources. One source of errors is erroneous linking of trees between the two data sources. Another source of error is that some tree crown segments contain more than one tree. However, this affects both the estimation with trees detected from TLS data as training data and the estimation with trees from the manual field inventory as training data.

The reason for the slightly lower accuracy with TLS data as training data is that the stem diameters of the tree stems detected from TLS data are not completely accurate. The estimates of DBH from ALS data with trees detected from TLS data as training data had a positive bias relative to the manually measured DBH. One reason is that the DBH in the training data had a positive bias. The DBH of all tree stems detected from TLS had no bias but the DBH of the subset that could be connected to tree crown segments in ALS data had a small positive bias. The reason might be that the segmentation of tree crowns in ALS data detects trees with large crowns more often than trees with small 
crowns; trees with large crowns have denser branches, causing an uncertainty in the DBH estimation from TLS data since the fitted circles are influenced by reflections from the branches. The estimates of stem volume from ALS data had a positive bias for all models relative to the stem volume from the manual field inventory. The stem volume in the training data was a function of DBH to the power of 1.8-2.2 (Brandel 1990) which is a convex function. Since there is an uncertainty in the $\mathrm{DBH}$, the calculated stem volume will always be greater than or equal to the real stem volume (Jensen 1906). The estimates from a weighted model based on trees from all species had a smaller bias. This is consistent with DBH having a larger coefficient in the stem volume function for spruce than for pine.

Previous studies have achieved slightly higher accuracy for estimation of tree level DBH, tree height and stem volume from ALS data (e.g., Vauhkonen et al. 2010; Persson et al. 2002; Solberg et al. 2006; Vauhkonen et al. 2008). None of those studies, however, used cross-validation or a separate validation dataset.

The accuracy of the estimates from ALS data using TLS data for training was almost as high as when using manual field inventory as training data. This means that the TLS-based method presented in this paper has the potential to become an important part of an automated forest inventory system. Additionally, TLS data offers the potential to determine timber quality of standing trees with high accuracy (Thies and Spiecker 2004) which is almost impossible to achieve with manual measurements as made in traditional forest inventory. New sensors such as distance cameras will make the equipment needed for the data collection more portable and the cost will most likely be lower. 


\section{Acknowledgements}

We would like to acknowledge Håkan Larsson at the Swedish Defense Research Agency who has collected, rectified and geo-referenced the TLS data. We would also like to acknowledge Blom Sweden that collected and preprocessed the ALS data. We would like to thank Heather Reese who has checked the language. This work was financed by the Swedish Research Council Formas. 


\section{References}

Aschoff T, Thies M, Spiecker H (2004) Describing forest stands using terrestrial laser-scanning. In: International Archives of Photogrammetry, Remote Sensing and Spatial Information Sciences, Istanbul, Turkey, 12-23 July, 2004. XXth ISPRS Congress: Proceedings of Commission V. Citeseer, XXXV (Part B5), pp 237-241

Axelsson P (2000) DEM generation from laser scanner data using adaptive TIN models. In: International Archives of Photogrammetry and Remote Sensing. International Society for Photogrammetry \& Remote Sensing, XXXIII (Part B4/1), pp 111-118

Axelsson PE (1999) Processing of laser scanner data - algorithms and applications. ISPRS Journal of Photogrammetry and Remote Sensing 54 (2-3):138-147

Bienert A, Scheller S, Keane E, Mohan F, Nugent C (2007) Tree detection and diameter estimations by analysis of forest terrestrial laserscanner point clouds. In: Rönnholm P, Hyyppä H, Hyyppä J (eds) International Archives of Photogrammetry, Remote Sensing and Spatial Information Sciences, Espoo, Finland, 12-14 September, 2007. ISPRS Workshop 'Laser Scanning 2007 and SilviLaser 2007'. XXXVI (Part 3/W52), pp $50-55$

Bland JM, Altman DG (1986) Statistical-methods for Assessing Agreement Between 2 Methods of Clinical Measurement. Lancet 1 (8476):307-310

Brandel G (1990) Volymfunktioner för enskilda träd : tall, gran och björk [Volume functions for individual trees : Scots pine (Pinus sylvestris), Norway spruce (Picea abies) and birch (Betula pendula \& Betula pubescens)]. 26. Swedish University of Agricultural Sciences, Institutionen för skogsproduktion (Department of Forest Yield Research), Garpenberg, Sweden

Falkowski MJ, Smith AMS, Hudak AT, Gessler PE, Vierling LA, Crookston NL (2006) Automated estimation of individual conifer tree height and crown diameter via two-dimensional spatial wavelet analysis of lidar data. Canadian Journal of Remote Sensing 32 (2):153-161 
Fritz A, Weinacker H, Koch B (2011) A method for linking TLS- and ALS-derived trees. In: Proceedings of SilviLaser 2011, University of Tasmania, in Hobart, Australia, 16-20 October, 2011.

Gonzalez R, Wintz P (1987) Digital image processing. 2 edn. Reading, MA: Addison-Wesley,

Gorte BGH, Pfeifer N (2004) Structuring laser-scanned trees using 3D mathematical morphology. In: International Archives of Photogrammetry, Remote Sensing and Spatial Information Sciences, Istanbul, Turkey, 12 23 July, 2004. XXth ISPRS Congress: Proceedings of Commission V. Citeseer, XXXV (Part B5), pp 929-933

Gupta S, Weinacker H, Koch B (2010) Comparative analysis of clustering-based approaches for 3-D single tree detection using airborne fullwave lidar data. Remote Sensing 2 (4):968-989

Henning JG, Radtke PJ (2006) Detailed stem measurements of standing trees from ground-based scanning lidar. Forest Science 52 (1):67-80

Hilker T, van Leeuwen M, Coops NC, Wulder MA, Newnham GJ, Jupp DLB, Culvenor DS (2010) Comparing canopy metrics derived from terrestrial and airborne laser scanning in a Douglas-fir dominated forest stand. Trees-Structure and Function 24 (5):819-832. doi:10.1007/s00468-010$0452-7$

Hirschmugl M (2008) Derivation of Forest Parameters from UltracamD Data. Dissertation, Graz University of Technology, Graz, Austria

Holm S (1977) Transformationer av en eller flera beroende variabler i regressionsanalys (in Swedish). HUGIN, vol 7. Stockholm, Sweden

Holmgren J, Barth A, Larsson H, Olsson H (2010) Prediction of stem attributes by combining airborne laser scanning and measurements from harvesting machinery. In: Proceedings of SilviLaser 2010, the 10th International Conference on LiDAR Applications for Assessing Forest Ecosystems, Freiburg, Germany, 14-17 September, 2010.

Hopkinson C, Chasmer L, Young-Pow C, Treitz P (2004) Assessing forest metrics with a ground-based scanning lidar. Canadian Journal of Forest ResearchRevue Canadienne De Recherche Forestiere 34 (3):573-583. doi:10.1139/x03-225

Hyyppä J, Kelle O, Lehikoinen M, Inkinen M (2001) A segmentation-based method to retrieve stem volume estimates from 3-D tree height models produced by laser scanners. IEEE Transactions on Geoscience and Remote Sensing 39 (5):969-975

InnovMetric SI (2010) PolyWorks: 3d scanner software. http://www.innovmetric.com/polyworks/3Dscanners/home.aspx?lang=en. Accessed 2010-12-30 2010

Jensen J (1906) Sur les fonctions convexes et les inégalités entre les valeurs moyennes. Acta Mathematica 30 (1):175-193

Király G, Brolly G (2007) Tree height estimation methods for terrestrial laser scanning in a forest reserve. In: Rönnholm P, Hyyppä H, Hyyppä J (eds) International Archives of Photogrammetry, Remote Sensing and Spatial 
Information Sciences, Espoo, Finland, 12-14 September, 2007. Proceedings of the ISPRS Workshop 'Laser Scanning 2007 and SilviLaser 2007'. XXXVI (Part 3/W52), pp 211-215

Lindberg E, Holmgren J, Olofsson K, Olsson H (2010) Estimation of stem attributes using a combination of terrestrial and airborne laser scanning. In: Proceedings of SilviLaser 2010, the 10th International Conference on LiDAR Applications for Assessing Forest Ecosystems, Freiburg, Germany, 14-17 September, 2010.

Lovell JL, Jupp DLB, Culvenor DS, Coops NC (2003) Using airborne and groundbased ranging lidar to measure canopy structure in Australian forests. Canadian Journal of Remote Sensing 29 (5):607-622

Maas HG, Bienert A, Scheller S, Keane E (2008) Automatic forest inventory parameter determination from terrestrial laser scanner data. Int J Remote Sens 29 (5):1579-1593. doi:10.1080/01431160701736406

Olofsson K, Lindberg E, Holmgren J (2008) A method for linking field-surveyed and aerial-detected single trees using cross correlation of position images and the optimization of weighted tree list graphs. In: Hill RA, Rosette J, Suárez J (eds) Proceedings of SilviLaser 2008, 8th international conference on LiDAR applications in forest assessment and inventory, Heriot-Watt University, Edinburgh, UK, 17-19 September, 2008. SilviLaser 2008 Organizing Committee, Edinburgh: Forest Research, Bournemouth UK, pp 95-104

Persson A, Holmgren J, Söderman U (2002) Detecting and measuring individual trees using an airborne laser scanner. Photogramm Eng Remote Sens 68 (9):925-932

Pfeifer N, Gorte BGH, Winterhalder D (2004) Automatic reconstruction of single trees from terrestrial laser scanner data. In: International Archives of Photogrammetry, Remote Sensing and Spatial Information Sciences, Istanbul, Turkey, 12-23 July, 2004. XXth ISPRS Congress: Proceedings of Commission V. Citeseer, XXXV (Part B5), pp 114-119

Pfeifer N, Winterhalder D (2004) Modelling of tree cross sections from terrestrial laser scanning data with free-form curves. In: International Archives of Photogrammetry, Remote Sensing and Spatial Information Sciences, Freiburg, Germany, 3-6 October, 2004. ISPRS working group VIII/2. Citeseer, XXXVI (Part 8/W2), pp 76-81

Pollock RJ (1996) The automatic recognition of individual trees in aerial images of forests based on a synthetic tree crown image model. Dissertation, University of British Columbia, Vancouver, Canada

Reitberger J, Schnorr C, Krzystek P, Stilla U (2009) 3D segmentation of single trees exploiting full waveform LIDAR data. ISPRS Journal of Photogrammetry and Remote Sensing 64 (6):561-574. doi:10.1016/j.isprsjprs.2009.04.002

Soininen A (2004) Terra Scan for MicroStation, user's guide. Terrasolid Ltd, Jyvaskyla, Finland 132 
Solberg S, Næsset E, Bollandsås OM (2006) Single tree segmentation using airborne laser scanner data in a structurally heterogeneous spruce forest. Photogramm Eng Remote Sens 72 (12):1369-1378

Thies M, Pfeifer N, Winterhalder D, Gorte BGH (2004) Three-dimensional reconstruction of stems for assessment of taper, sweep and lean based on laser scanning of standing trees. Scandinavian Journal of Forest Research 19 (6):571-581. doi:10.1080/02827580410019562

Thies M, Spiecker H (2004) Evaluation and future prospects of terrestrial laser scanning for standardized forest inventories. In: International Archives of Photogrammetry, Remote Sensing and Spatial Information Sciences, Freiburg, Germany, 3-6 October, 2004. ISPRS working group VIII/2. Citeseer, XXXVI (Part 8/W2), pp 192-197

Van Leeuwen M, Coops NC, Wulder MA (2010) Canopy surface reconstruction from a LiDAR point cloud using Hough transform. Remote Sensing Letters 1 (3):125-132. doi:10.1080/01431161003649339

Watt PJ, Donoghue DNM (2005) Measuring forest structure with terrestrial laser scanning. Int J Remote Sens 26 (7):1437-1446. doi:10.1080/01431160512331337961

Vauhkonen J, Korpela I, Maltamo M, Tokola T (2010) Imputation of single-tree attributes using airborne laser scanning-based height, intensity, and alpha shape metrics. Remote Sensing of Environment 114:1263-1276

Vauhkonen J, Tokola T, Maltamo M, Packalén P (2008) Effects of pulse density on predicting characteristics of individual trees of Scandinavian commercial species using alpha shape metrics based on airborne laser scanning data. Canadian Journal of Remote Sensing 34:441-459

Wezyk P, Koziol K, Glista M, Pierzchalski M (2007) Terrestrial laser scanning versus traditional forest inventory First results from the polish forests. In: Rönnholm P, Hyyppä H, Hyyppä J (eds) International Archives of Photogrammetry, Remote Sensing and Spatial Information Sciences, Espoo, Finland, 12-14 September, 2007. ISPRS Workshop 'Laser Scanning 2007 and SilviLaser 2007'. XXXVI (Part 3/W52), pp 424-429 